\title{
Simultaneous analysis of all single-nucleotide polymorphisms in genome-wide association study of rheumatoid arthritis George Mathew* ${ }^{*}$, Hongyan $\mathrm{Xu}^{2}$ and Varghese George ${ }^{2}$
}

Addresses: ${ }^{1}$ Department of Mathematics, Missouri State University, 901 South National Avenue, Springfield, MO 65897, USA and ${ }^{2}$ Department of Biostatistics, Medical College of Georgia, 1120 15th Street, Augusta, GA 30912, USA

E-mail: George Mathew* - georgemathew@missouristate.edu; Hongyan Xu - hxu@mcg.edu; Varghese George - vgeorge@mcg.edu ${ }^{*}$ Corresponding author

from Genetic Analysis Workshop 16

St Louis, MO, USA 17-20 September 2009

Published: 15 December 2009

BMC Proceedings 2009, 3(Suppl 7):SII doi: 10.1186/I753-656I-3-S7-SII

This article is available from: http://www.biomedcentral.com/I753-656I/3/S7/SII

(c) 2009 Mathew et al; licensee BioMed Central Ltd.

This is an open access article distributed under the terms of the Creative Commons Attribution License (http://creativecommons.org/licenses/by/2.0), which permits unrestricted use, distribution, and reproduction in any medium, provided the original work is properly cited.

\begin{abstract}
The availability of very large number of markers by modern technology makes genome-wide association studies very popular. The usual approach is to test single-nucleotide polymorphisms (SNPs) one at a time for association with disease status. However, it may not be possible to detect marginally significant effects by single-SNP analysis. Simultaneous analysis of SNPs enables detection of even those SNPs with small effect by evaluating the collective impact of several neighboring SNPs. Also, false-positive signals may be weakened by the presence of other neighboring SNPs included in the analysis. We analyzed the North American Rheumatoid Arthritis Consortium data of Genetic Analysis Workshop 16 using HLasso, a new method for simultaneous analysis of SNPs. The simultaneous analysis approach has excellent control of type I error, and many of the previously reported results of single-SNP analyses were confirmed by this approach.
\end{abstract}

\section{Background}

The increase in genome-wide experiments and sequencing of multiple genomes has resulted in the availability of large data sets for genome-wide association studies (GWAS) of complex diseases. The usual procedure is to test these single-nucleotide polymorphisms (SNPs) one by one for association with the disease status. This means one will be testing the marginal effect of a SNP on a disease without consideration of any other interacting SNPs in the model. This approach will inherently increase the overall probability of false positives [1]. Because complex diseases arise from many, possibly interacting, genes from the genome, it would be more appropriate to study the effect of several genes jointly rather than testing each of them separately [2]. The single-SNP analysis may ignore information provided by a joint distribution [3].

The North American Rheumatoid Arthritis Consortium (NARAC) data of Genetic Analysis Workshop (GAW) 16 provides an excellent opportunity to analyze simultaneously a very large collection of SNPs for GWAS. We adopt a recently developed method [4] for the simultaneous analysis of SNPs from the NARAC data. This method is useful when the number of SNPs is much greater than the number of individuals in a case-control 
study. The procedure is formulated as a problem of variable selection in a logistic regression framework by treating each SNP as a covariate. It attempts to find a collection of SNPs to obtain the "best" model to explain the disease status for a specified error rate.

\section{Methods}

The NARAC data consists of 868 cases of rheumatoid arthritis (RA) and 1194 controls. The software program HLasso [4] was employed for the simultaneous analysis of SNPs. The program adopts a Bayesian approach for logistic regression and makes use of the normalexponential-gamma (NEG) probability density function as the penalty function (see Hoggart et al. [4] for details). The NEG probability density function has two parameters, a scale parameter $\gamma$ and a shape parameter $\eta$. As both $\gamma$ and $\eta$ increase such that $\sqrt{2 \eta} / \gamma$ remains a constant, say $\lambda$, the NEG converges to the double exponential distribution with rate parameter $\lambda$. The predictors in the logistic regression model are the SNP genotypes, coded as 0,1 , and 2 , corresponding to an additive model. These coded values are standardized to have mean zero and unit variance. The procedure searches for a collection of SNPs for which the posterior mode is positive. A positive posterior mode indicates a signal of association that is strong enough to overcome the prior preference of zero effect, and the corresponding set of SNPs are declared as significantly associated with the disease.

Further analysis was done to identify whether the SNPs declared significant by this method confirms the earlier findings by single-marker analyses. We examined whether the markers identified as significant by the simultaneous approach are in high linkage disequilibrium (LD) with SNPs that are already identified to be associated with the disease. Particular attempt was made to test SNPs identified by single-marker analysis on chromosomes 1, 6, and 9 from other data sets. The software package Haploview [5] was used to compute the pair-wise LD for SNPs on the chromosomes.

\section{Results}

Chromosomes 1 through 22 were analyzed. Table 1 provides the number of SNPs found to be significant on each chromosome. From a total of 531,689 SNPs, 2627 SNPs were found to be significantly associated with the disease by this procedure, yielding an upper bound of $0.4941 \%$ for the empirical type I error rate.

The logistic regression model, logit $(\mathrm{P}($ affected $))=$ $\beta_{0}+\sum_{i=1}^{n} \beta_{i}(S N P)_{i}$, was employed for the analyses. When a marker is declared significant, the estimate $\hat{\beta}_{i}$ of $\beta$ provides an estimate of the effect of that marker on the affection status of the disease. An estimate of the odds ratio (OR) for the disease is $\exp \left(\hat{\beta}_{i}\right)$. This means that $\mathrm{OR}>1$ if $\hat{\beta}_{i}>0$, and $\mathrm{OR}<1$ if the $\hat{\beta}_{i}<0$. Therefore, when $\hat{\beta}_{i}>0$, the allele coded as " 1 " increases the disease risk; and when $\hat{\beta}_{i}<0$, the allele coded as " 1 " has a protective effect and decreases the disease risk. Table 1 also provides the marker with the largest risk effect value and the marker with the largest protective effect value on each chromosome.

It is well known that HLA-DRB1 region on chromosome 6 is associated with RA. In the HLA-DRB1 region the marker rs602875 at position $32.68 \mathrm{Mb}$ was identified to be significant in our study. By single-SNP analysis of a different data set, Chang et al. identified the marker rs1953126 near the TRAF1-C5 region on chromosome 9 to be associated with RA [6]. Also, Plenge et al., through single SNP analysis, identified the markers rs3761847 and rs2900180 in the same region to be of risk for RA [7]. In our simultaneous analysis, the marker rs 3933326 near the TRAF1-C5 region was identified to be significant, which is in high LD with the markers rs1953126, rs3761847, and rs2900180. Begovich et al. [8] identified the marker rs2476601 in the PTPN22 region of chromosome 1 to be associated with risk for RA. The simultaneous analysis also identified this marker to be associated with RA, confirming the earlier findings.

\section{Discussion}

The type I error is given by $\alpha=2-2 \Phi\left(f^{\prime} \sqrt{\frac{n_{0}+n_{1}}{n_{0} n_{1}}}\right)$, where $f^{\prime}$ is the derivative of $-\log (\mathrm{NEG})$ at the origin (which is the derivative of the double exponential distribution with parameter $\gamma=\sqrt{2 \eta} / \gamma$ at the origin), $n_{0}$ is the number of cases, $n_{1}$ is the number of controls, and $\Phi$ is the cumulative distribution function of the standard normal distribution [4]. For our computations, we set $\lambda$ to be 50 and the shape parameter $\eta$ to be 0.1 , so that the calculated value of $\alpha=0.025$. The simultaneous analysis identified only $0.4941 \%$ of SNPs to be significantly associated with RA. Because the vast majority of the SNPs are not associated with RA, this is a conservative estimate of the empirical type I error. Comparing this with the nominal level of 0.025 , it is evident that the simultaneous analysis procedure has excellent control of type I error.

In modeling all SNPs simultaneously, the HLasso program includes a SNP in the model if it significantly improves prediction of case-control status beyond that obtained from SNPs already included in the model [4]. Problems could arise when there are two or more tightly linked causal markers. In this case, if HLasso chooses only one marker, its effect could be inflated. For 
Table I: Number of significant markers identified by the simultaneous analysis and markers with extreme effect sizes

\begin{tabular}{|c|c|c|c|c|c|c|}
\hline \multirow[t]{3}{*}{ Chromosome number } & \multirow[t]{3}{*}{ Number of SNPs } & \multirow[t]{3}{*}{ Number of significant SNPs } & \multicolumn{4}{|c|}{ Markers with largest risk and protective effects } \\
\hline & & & \multicolumn{2}{|c|}{ Largest risk effect } & \multicolumn{2}{|c|}{ Largest protective effect } \\
\hline & & & Marker & Effect size & Marker & Effect size \\
\hline 1 & 40929 & 142 & rs7519615 & I.73638 & rs2275864 & $-1.4 \mid 482$ \\
\hline 2 & 44090 & 140 & rs655783 & 0.91779 & rs938869 & -2.3145 \\
\hline 3 & 36690 & 138 & rs7616866 & 202.447 & rs9288967 & -4.23478 \\
\hline 4 & 32628 & 133 & rs768063 & 155.04 & rs6816684 & -2.31044 \\
\hline 5 & 33612 & 90 & rs344I56 & $\mathrm{I} .46745$ & rs6899062 & -1.68164 \\
\hline 6 & 35574 & 82 & rs6935937 & 3.06767 & rs|856363 & -2.18496 \\
\hline 7 & 29244 & 130 & rs9632680 & 96.105 & rs4732523 & -2.41344 \\
\hline 8 & 30990 & 130 & rs7006628 & $0.5779 \mid 4$ & rs2853259 & -1.50527 \\
\hline 9 & 26128 & 125 & rs64788I5 & 154.845 & rs|387292 & -3.12822 \\
\hline 10 & 28331 & $13 \mid$ & rs2388I2I & $0.777 \mid 84$ & rs 1909668 & -1.36459 \\
\hline II & 26477 & 119 & rs 1879445 & $|23.08|$ & rs7932437 & -6.04313 \\
\hline 12 & 26365 & 129 & rsll46II4 & I.43868 & rs7300982 & -1.59685 \\
\hline 13 & 20242 & 129 & rs2323883 & 4.76091 & rs9740397 & -3.53682 \\
\hline 14 & I795| & 124 & rs4296166 & I.53678 & rs4983565 & $-2.025 \mid 2$ \\
\hline 15 & 16166 & 121 & rs7183817 & $0.8 \mid 4795$ & rs3743372 & -2.60765 \\
\hline 16 & 16460 & 111 & rs4238802 & 0.66247 & rs4783। 87 & -1.98159 \\
\hline 17 & 14027 & 123 & rs2880328 & 92.8919 & rs9747823 & $-1.3 \mid 507$ \\
\hline 18 & 16450 & 123 & rs2303508 & 78.2526 & rs|982040 & -2.32656 \\
\hline 19 & 9236 & 101 & rs3810256 & I.II899 & rs 10404348 & -3.04764 \\
\hline 20 & 13843 & 114 & rs6513195 & 3.13637 & rs613860I & -4.63256 \\
\hline 21 & 8051 & 102 & rs2823819 & 0.971309 & rsI539902 & -1.08918 \\
\hline 22 & 8205 & 90 & rs761917 & I.46745 & rsI7406434 & -1.68164 \\
\hline Total & 531689 & 2627 & & & & \\
\hline
\end{tabular}

example, the marker rs7616866 on chromosome 3 at position 64317576 had the largest effect size 202.447, and was found to be significant. The LD values, $D^{\prime}$, of this marker with the markers rs9812599 at 64315677 , rs7615058 at 64321040 , rs6445398 at 64309797, and rs1860819 at 64323994 are $0.857,0.769,1.0$, and 0.977 , respectively. When there is high pair-wise $\mathrm{LD}$ between markers, multicollinearity is present, and in such cases it is not possible to make meaningful statements about individual effect sizes. However, the overall model is valid in predicting the disease status of the disease.

The simultaneous analysis of SNPs confirmed several previous findings of causal variants for RA: the HLADRB1 region of chromosome 6, the TRF1-C5 region on chromosome 9, and the PTPN22 region on chromosome 1. However, it did not confirm the findings on the PADI4 region on chromosome 1 , known to be a causal variant for RA [10].

We did not check for population stratification because the samples were from Caucasian population, which is expected to be relatively homogeneous. However, Sarasu et al. [9] suggests that population stratification is present in the data. The method we use seems to be reasonably robust to population stratification because type I error is well controlled. The SNP data had already been checked for errors [11], and hence, no further checking for errors was done. There were many significant markers on each chromosome. We checked whether these markers were themselves in high LD with each other. Five pairs among them on chromosome 6 were found to be in high LD, and none were found on any other chromosomes. It could be due to the fact that HLasso program includes a SNP in the model if it significantly improves prediction of casecontrol status beyond that obtained from the SNP already included. If there are two strongly correlated predictors, and if the marginal increase is minimal, then the program is inclined to choose only one of the two predictors.

\section{Conclusion}

The simultaneous analysis of all SNPs using HLasso reduced considerably the overall probability for false positives. The method confirmed many of the previous findings by the single-SNP analysis.

\section{List of abbreviations used}

GWAS: Genome-wide association studies; LD: Linkage disequilibrium; NARAC: North American Rheumatoid Arthritis Consortium; NEG: Normal-exponentialgamma; OR: odds ratio; RA: Rheumatoid arthritis; SNP: Single-nucleotide polymorphism.

\section{Competing interests}

The authors declare that they have no competing interests. 


\section{Authors' contributions}

GM performed the analysis and drafted the manuscript. HX conceived of the study, participated in the analysis and helped to draft the manuscript. VG participated in the design and coordination of the study. All authors read and approved the final manuscript.

\section{Acknowledgements}

The Genetic Analysis workshops are supported by $\mathrm{NIH}$ grant ROI GM03 I575 from the National Institute of General Medical Sciences.

This article has been published as part of BMC Proceedings Volume 3 Supplement 7, 2009: Genetic Analysis Workshop 16. The full contents of the supplement are available online at http://www.biomedcentral.com/ $\underline{1753-6561 / 3 \text { ? issue }=\text { S7. }}$.

\section{References}

I. Rish $\mathrm{N}$ and Merikangas $\mathrm{K}$ : The future of genetic studies of complex human diseases. Science 1996, 273:1516-1517.

2. Hoh J, Wille $A$ and Ott J: Trimming, weighing, and grouping SNPs in human case-control association studies. Genome Res 200I, II:2II5-2II9.

3. Balding DJ: A tutorial on statistical methods for population association studies. Nat Rev Genet 2006, 7:78I-79I.

4. Hoggart C], Whittaker JC, De lorio $M$ and Balding DJ: Simultaneous analysis of all SNPs in genome-wide and re-sequencing association studies. PLoS Genetics 2008, 4: el000I30.

5. Barrett JC, Fry B, Maller J and Daly MJ: Haploview: analysis and visualization of LD and haplotype maps. Bioinformatics 2005 , 21:263-265.

6. Chang M, Rowland CM, Garcia VE, Schrodi SJ, Catanese JJ, Helm-van Mil van der AH, Ardlie KG, Amos Cl, Criswell LA, Kastner DL, Gregersen PK, Kurreeman FA, Toes RE, Huizinga TW, Seldin MF and Begovich $A B$ : A large-scale rheumatoid arthritis genetic study identifies association at chromosome 9q33.2. PLoS Genetics 2008, 4:el000I07.

7. Plenge RM, Seielstad M, Padyukov L, Lee AT, Remmers EF, Ding B, Liew A, Khalili H, Chandrasekaran A, Davies LR, Li W, Tan AK, Bonnard C, Ong RT, Thalamuthu A, Pettersson S, Liu C, Tian C, Chen WV, Carulli JP, Beckman EM, Altshuler D, Alfredsson L, Criswell LA, Amos CI, Seldin MF, Kastner DL, Klareskog L and Gregersen PK: TRAFI-C5 as a risk locus for rheumatoid arthritis - a genomewide study. N Engl J Med 2007, 357:1199-1209.

8. Begovich $A B$, Carlton VE, Honigberg LA, Schrodi SJ, Chokkalingam AP, Alexander HC, Ardlie KG, Huang Q, Smith AM, Spoerke JM, Conn MT, Chang M, Chang SY, Saiki RK, Catanese IJ, Leong DU, Garcia VE, McAllister LB, Jeffery DA, Lee AT, Batliwalla F, Remmers E, Criswell LA, Seldin MF, Kastner DL, Amos Cl, Sninsky J] and Gregersen PK: A missense single-nucleotide polymorphism in a gene encoding a protein tyrosine phosphatase (PTPN22) is associated with rheumatoid arthritis. Am J Hum Genet 2004, 75:330-337.

9. Sarasua SM, Collins JS, Williamson D, Satten GA and Allen AS: Effect of population stratification on the identification of significant single-nucleotide polymorphisms in case-control studies. BMC Proc 2009, 3(suppl 7):SI3.

10. Plenge RM, Padyukov L, Remmers EF, Purcell S, Lee AT, Karlson EW, Wolfe F, Kastner DL, Alfredsson L, Altshuler D, Gregersen PK, Klareskog $L$ and Rioux JD: Replication of putative candidategene associations with rheumatoid arthritis in $>4,000$ samples from North America and Sweden: association of susceptibility with PTPN22, CTLA4, and PADI4. Am J Hum Genet 2005, 77:1044-1060.

II. Amos Cl, Chen WV, Remmers E, Siminovitch KA, Seldin MF, Criswell LA, Lee AT, John S, Shephard ND, Worthington J, Cornelis F, Plenge RM, Begovich AB, Dyer TD, Kastner DL and Gregersen PK: Data for Genetic Analysis Workshop (GAW) 15 Problem 2, genetic causes of rheumatoid arthritis and associated traits. BMC Proc 2007, I (suppI I):S3.

\section{Publish with BioMed Central and every scientist can read your work free of charge}

"BioMed Central will be the most significant development for disseminating the results of biomedical research in our lifetime. "

Sir Paul Nurse, Cancer Research UK

Your research papers will be:

- available free of charge to the entire biomedical community

- peer reviewed and published immediately upon acceptance

- cited in PubMed and archived on PubMed Central

- yours - you keep the copyright
BioMedcentral 